\title{
Benazepril hydrochloride protects against doxorubicin cardiotoxicity by regulating the PI3K/Akt pathway
}

\author{
LAN ZHAN $^{1}$, XIANGXIU WANG ${ }^{1}$, YANJING ZHANG ${ }^{1}$, GUONIAN ZHU ${ }^{1}$, \\ YU DING $^{1}$, XUEMEI CHEN ${ }^{1}$, WEI JIANG ${ }^{2}$ and SISI WU ${ }^{1}$ \\ ${ }^{1}$ Core Facilities; ${ }^{2}$ Molecular Medicine Research Center, State Key Laboratory of Biotherapy, \\ West China Hospital, Sichuan University, Chengdu, Sichuan 610041, P.R. China
}

Received October 15, 2020; Accepted July 8, 2021

DOI: $10.3892 /$ etm.2021.10516

\begin{abstract}
Doxorubicin (DOX) stimulates the generation of reactive oxygen species, thereby impairing mitochondrial functions. Angiotensin-converting enzyme inhibitors (ACEIs) have been identified to exhibit protective effects on cardiovascular diseases. The present study aimed to test the hypothesis that an ACEI benazepril hydrochloride $(\mathrm{HCl})$ may protect against DOX-induced cardiotoxicity. The DOX injury model was established using rat embryonic cardiac myoblast cells (H9c2 cell line) treated with DOX in vitro. H9c2 cells were treated with benazepril-HCl, DOX or a mixture of DOX and benazepril- $\mathrm{HCl}$ to measure the activities of myocardial enzymes including lactate dehydrogenase (LDH), superoxide dismutase, catalase and glutathione peroxidase, in addition to the concentration of malondialdehyde in the culture medium. Cells without any treatment were used as a control. DOX treatment increased the levels of activity of myocardial enzymes in H9c2 cells compared with those in the untreated control cells. Additionally, co-treatment with benazepril- $\mathrm{HCl}$ significantly reduced the levels of apoptosis occurring due to DOX-mediated cellular damage. The mechanistic experiment revealed that pretreatment with benazepril- $\mathrm{HCl}$ counteracted the DOX-induced oxidative stress and suppressed the activation of apoptosis via the PI3K/Akt signaling pathway. By contrast, an Akt inhibitor (MK2206) inhibited the protective effects of benazepril- $\mathrm{HCl}$ against DOX-induced H9c2 cell injury, as revealed by increased $\mathrm{LDH}$ release in $\mathrm{H} 9 \mathrm{c} 2$ cells. These results
\end{abstract}

Correspondence to: Mrs Sisi Wu, Core Facilities, West China Hospital, Sichuan University, 1 Keyuan 4th Road, Gao Peng Street, Chengdu, Sichuan 610041, P.R. China

E-mail: sisigia@163.com

Professor Wei Jiang, Molecular Medicine Research Center, State Key Laboratory of Biotherapy, West China Hospital, Sichuan University, 1 Keyuan 4th Road, Gao Peng Street, Chengdu, Sichuan 610041, P.R. China

E-mail: wcumsjw@scu.edu.cn

Key words: benazepril hydrochloride, doxorubicin, H9c2 cells, cardiotoxicity, apoptosis, oxidative stress suggested that benazepril-HCl may potentially be administered as an adjuvant for DOX in long-term clinical use.

\section{Introduction}

Doxorubicin (DOX), an anthracycline chemotherapeutic drug, is one of the most potent, effective and commonly used anticancer chemotherapeutics (1). However, its clinical use is hampered due to its acute and chronic cardiotoxic effects, as long-term use of DOX can result in left ventricular dysfunction and ultimately heart failure $(2,3)$. Previous studies have revealed that DOX treatment leads to excess free radicals and reactive oxygen species (ROS) in the myocardium $(4,5)$. These radicals induce potential redox-associated damage through both enzymatic and non-enzymatic pathways (6). Lipid peroxidation is induced by DOX-generated free radicals, which eventually leads to cell membrane damage (7). Additionally, mitochondrial damage, increase in $\mathrm{Ca}^{2+}$ currents with subsequent sarcoplasmic reticulum dysfunction and decreased activity of $\mathrm{Na} / \mathrm{K}$-ATPase have been implicated in DOX-induced cardiotoxicity $(8,9)$. Morphological alterations in DOX-treated myocardium primarily include myofibrillar loss, dilatation of the sarcoplasmic reticulum and swollen mitochondria (10). Destruction of the generated ROS by antioxidants has been demonstrated to induce protective effects against DOX-induced cardiomyopathy (11). For example, antioxidants such as Bombyx mori, benazepril and quercetin have been used to protect against DOX-induced cardiotoxicity in previous studies $(12,13)$.

Angiotensin-converting enzyme inhibitors (ACEIs), including zofenopril (14), lisinopril (15), enalapril (16) and dexrazoxane (17), have been proposed as another potential preventive strategy for DOX-induced cardiac dysfunction and injury. In rats treated with short- or long-term DOX, co-administration of ACEIs haa been reported to restore their cardiac function (18). In addition, in rats and mice suffering from pathological cardiovascular conditions (such as spontaneous hypertension, cardiomyopathy, diastolic heart failure or myocardial infarction) as a result of experimental autoimmune myocarditis, DOX treatment, hyperglycemia, inhibition of the renin-angiotensin system by ACEIs or angiotensin receptor blockers results in a decrease in the expression levels of NADPH oxidase (Nox) subunits p22phox, Nox2, p47phox and p67phox (19). 
Benazepril (brand name Lotensin) is an ACEI and has been used for the treatment of congestive heart failure, hypertension and chronic renal failure $(20,21)$. A number of studies have confirmed that benazepril protects against DOX-induced renal dysfunction (22-24). However, to the best of our knowledge, there are currently no studies on the role of benazepril in DOX-induced cardiac toxicity. Since DOX toxicity is mainly associated with the heart, the present study aims to explore the potential beneficial effects and mechanisms of benazepril hydrochloride $(\mathrm{HCl})$ for DOX-induced cardiotoxicity in rat embryonic cardiac myoblast (H9c2) cells, which may provide the clinical foundation for the use of benazepril along with DOX to alleviate DOX-induced cardiotoxicity.

\section{Materials and methods}

Chemicals and reagents. Benazepril-HCl (cat. no. S1284; Selleck Chemicals) was dissolved in DMSO to obtain a solution of $10 \mathrm{mM}$. The purity was determined to be $>99 \%$ by high performance liquid chromatography. DOX (cat. no. 25316-40-9; MilliporeSigma) was dissolved in saline to generate a stock solution of $100 \mu \mathrm{M}$ and was diluted to a final concentration of $2 \mu \mathrm{M}$ for all experiments unless otherwise specified. The Akt inhibitor MK2206 was purchased from MedChemExpress (cat. no. HY-108232).

Cell culture. Rat H9c2 cells were obtained from The Cell Bank of Type Culture Collection of The Chinese Academy of Sciences. Cells were cultured in DMEM-high glucose medium supplemented with 10\% FBS (both Gibco; Thermo Fisher Scientific, Inc.) and antibiotics (1\% penicillin/streptomycin) at $37^{\circ} \mathrm{C}$ in $5 \% \mathrm{CO}_{2}$ and $95 \% \mathrm{O}_{2}$ with saturated humidity.

Total RNA extraction and reverse transcription-quantitative $P C R$. Total RNA was isolated from the $\mathrm{H} 9 \mathrm{c} 2$ cells using the TRIzol ${ }^{\circledR}$ reagent (cat. no. 15596026; Invitrogen; Thermo Fisher Scientific, Inc.) according to the manufacturer's instructions. The iScript ${ }^{\mathrm{TM}}$ RT Supermix (Bio-Rad Laboratories, Inc.) was used to produce cDNA. The reverse transcription reaction mix was added to $2 \mu \mathrm{g}$ total RNA and incubated at $25^{\circ} \mathrm{C}$ for $5 \mathrm{~min}$ for priming, at $46^{\circ} \mathrm{C}$ for $20 \mathrm{~min}$ for reverse transcription, and then inactivated for $1 \mathrm{~min}$ at $95^{\circ} \mathrm{C}$. SYBR-Green master mix (Bio-Rad Laboratories, Inc.) was used for Quantitative real-time PCR reactions, which were performed as follows: $30 \mathrm{sec}$ at $95^{\circ} \mathrm{C}$, and 40 cycles of $95^{\circ} \mathrm{C}$ for $5 \mathrm{sec}$ and $60^{\circ} \mathrm{C}$ for $30 \mathrm{sec}$. The mRNA expression of the $A C E$ gene was determined using the $2^{-\Delta \Delta \mathrm{Cq}}$ method (25). $\beta$-actin was used as an internal reference. The specific primer sequences used were as follows: ACE forward, 5'-GCCTCCCAACGAGTTAGAAGA G-3' and reverse, 5'-CGGGACGTGGCCATTATATT-3' (19); $\beta$-actin forward, 5'-TGCCTGACGGTCAGGTCA-3' and reverse, 5'-CAGGAAGGAAGGCTGGAAG-3'. The primers were synthesized by Chengdu TsingKe Biotechnology Co., Ltd.

Cell viability assay and lactate dehydrogenase $(\mathrm{LDH})$ release. The viability of $\mathrm{H} 9 \mathrm{c} 2$ cells was measured using Cell Counting Kit-8 (CCK-8; Dojindo Molecular Technologies, Inc.). Briefly, $\mathrm{H} 9 \mathrm{c} 2$ cells were seeded into a 96-well plate with each well containing 5,000 cells $/ 100 \mu \mathrm{l}$ and pre-incubated at $37^{\circ} \mathrm{C}$ with $5 \% \mathrm{CO}_{2}$ for $24 \mathrm{~h}$. Cells were pretreated with benazepril- $\mathrm{HCl}$ at different concentrations (10 and $100 \mathrm{nM}, 1,10$ and $100 \mu \mathrm{M})$ for $1 \mathrm{~h}$ at $37^{\circ} \mathrm{C}$, followed by treatment with DOX $(2 \mu \mathrm{M})$ for $24 \mathrm{~h}$ at $37^{\circ} \mathrm{C}$. After treatment, $10 \mu \mathrm{l}$ of CCK-8 solution was added for incubation at $37^{\circ} \mathrm{C}$ for $2 \mathrm{~h}$. Absorbance at $450 \mathrm{~nm}$ was read using a microplate reader (BioTek Instruments, Inc.). The average optical density (OD) of five wells for each group was measured to determine the percentage of viable cells: $\%$ Of viable cells $=$ mean OD after treatment $/$ mean OD of controls x100.

H9c2 cells were plated $2 \times 10^{5}$ cell $/ \mathrm{ml}$ in a $90-\mathrm{mm}$ dish, treated with $0.1 \%$ DMSO (control group) or benazepril- $\mathrm{HCl}$ $(1 \mu \mathrm{M})$ for $1 \mathrm{~h}$ at $37^{\circ} \mathrm{C}$, and cultured in the presence or absence of DOX $(2 \mu \mathrm{M})$ for an additional $24 \mathrm{~h}$ at $37^{\circ} \mathrm{C}$. The medium was collected by centrifugation at $500 \mathrm{x}$ g for $5 \mathrm{~min}$ at room temperature. The $\mathrm{LDH}$ release was measured in the cell medium using an LDH assay kit (cat. no. A020-2-2; Nanjing Jiancheng Bioengineering Institute). LDH activity was presented as units per liter. The level of LDH activity was calculated using the formula: LDH Activity=[amount (nmol) of $\mathrm{NADH}$ generated/min]/[volume of supernatant used $(\mathrm{ml})$ ] x sample dilution factor.

Assessment of H9c2 apoptosis. Apoptosis was evaluated by flow cytometry with an Annexin V-APC/7-AAD Apoptosis Detection kit (cat. no. 640930; BioLegend, Inc.). Cells were washed with PBS twice and resuspended in $100 \mu 11 \mathrm{X}$ annexin-binding buffer at a concentration of $1 \times 10^{6}$ cells $/ \mathrm{ml}$. Each $100 \mu \mathrm{l}$ cell solution was incubated with $5 \mu \mathrm{l}$ annexin $\mathrm{V}$-APC and $1 \mu 17-\mathrm{AAD}(1 \mu \mathrm{M})$ at $37^{\circ} \mathrm{C}$ in a $\mathrm{CO}_{2}$ incubator for $15 \mathrm{~min}$. Following the addition of $400 \mu \mathrm{l} 1 \mathrm{X}$ annexin-binding buffer into each solution, cells were analyzed by a FACS Aria SORP (BD Biosciences). The average early and late apoptotic percentage of cells was determined with three repeats, which were analyzed using BD CellQuest Pro software version 5.2.1 (Becton-Dickinson and Company).

Measurement of mitochondrial ROS. The ROS level was detected with a fluorescent probe 2',7'-dichlorofluorescein diacetate (DCFH-DA; cat. no. C6827; Thermo Fisher Scientific, Inc.) in H9c2 cells as previously described (23). Briefly, H9c2 cells were treated with vehicle or DOX $(2 \mu \mathrm{M})$ in the presence or absence of benazepril- $\mathrm{HCl}(1 \mu \mathrm{M}$ for $1 \mathrm{~h}$ prior to DOX exposure) for $24 \mathrm{~h}$ at $37^{\circ} \mathrm{C}$ and rinsed with PBS. Subsequently, the cells were incubated for $1 \mathrm{~h}$ at $37^{\circ} \mathrm{C}$ with $10 \mu \mathrm{M}$ DCFH-DA in PBS. After washing twice with PBS to remove extracellular DCFH-DA, images were captured at room temperature using a Zeiss OBSERVER D1/AX10 cam (Carl Zeiss AG). Fluorescence intensity was measured using a microplate reader (Synergy Mx; BioTek Instruments, Inc.) at $488 \mathrm{~nm}$ excitation and $525 \mathrm{~nm}$ emission wavelengths.

Analysis of malondialdehyde (MDA) content and superoxide dismutase (SOD), catalase (CAT) and glutathione peroxidase $(G S H-P x)$ activities. H9c2 cells were harvested using a RIPA lysis buffer (cat. no. P0013K; Beyotime Institute of Biotechnology) and centrifuged at $12,000 \mathrm{x} \mathrm{g}$ for $10 \mathrm{~min}$ at $4^{\circ} \mathrm{C}$. The supernatants were used to assess the concentration of MDA (cat. no. S0131S; Beyotime Biotechnology) and the activities of SOD (cat. no. S0101), CAT (cat. no. S0051) and GSH-Px (cat. no. S0056) (all from Beyotime Institute of 
Biotechnology) using the corresponding detection kits. All samples were immediately analyzed or frozen at $-80^{\circ} \mathrm{C}$ for up to one month. The total protein amount was determined by a BCA protein assay kit (Beyotime Institute of Biotechnology). The level of MDA was expressed as nmol/mg protein. The activity levels of SOD, CAT and GSH-Px were expressed as $\mathrm{U} / \mathrm{mg}$ protein by normalizing against the total protein concentration in each sample.

Western blotting. $\mathrm{H} 9 \mathrm{c} 2$ cells were seeded in 6-cm dishes preincubated in a humidified incubator at $37^{\circ} \mathrm{C}$ with $5 \% \mathrm{CO}_{2}$ for $24 \mathrm{~h}$. The cells were pretreated with an Akt inhibitor MK2206 $(1 \mu \mathrm{M})$ for $30 \mathrm{~min}$ and incubated with benazepril- $\mathrm{HCl}(1 \mu \mathrm{M})$ for $1 \mathrm{~h}$ at $37^{\circ} \mathrm{C}$, followed by DOX $(2 \mu \mathrm{M})$ for $24 \mathrm{~h}$ at $37^{\circ} \mathrm{C}$. Cells treated with DOX and/or benazepril- $\mathrm{HCl}$ were obtained, washed with PBS and lysed in RIPA lysis buffer containing a 1X phosphatase and protease inhibitor cocktail (Roche Molecular Diagnostics) for $30 \mathrm{~min}$ on ice. Protein concentrations were determined using a BCA kit (cat. no. P0009; Beyotime Institute of Biotechnology). Samples containing $40 \mu \mathrm{g}$ protein were boiled in $1 \mathrm{X}$ loading buffer (0.05 M Tris-HCl, 0.1 M DTT, $70 \mathrm{mM}$ SDS, $1.5 \mathrm{mM}$ bromophenol blue and $1.0 \mathrm{M}$ glycerol) for $5 \mathrm{~min}$. Then, equal amounts of protein (40 $\mu \mathrm{g} /$ lane protein) were separated by $12 \%$ SDS-PAGE, and electroblotted onto PVDF membranes (MilliporeSigma). The membranes were blocked with a blocking buffer [5\% (w/v) non-fat milk powder in Tris-buffered saline with $0.1 \%$ Tween-20 (Bio-Rad Laboratories, Inc.) (TBST)] for $1 \mathrm{~h}$ at room temperature, and incubated overnight with primary antibodies at $4^{\circ} \mathrm{C}$. Following washing by TBST, the membranes were incubated with secondary antibodies for $1 \mathrm{~h}$ at room temperature, followed by three additional TBST washes. Primary antibodies against GAPDH (1:2,000; cat. no. sc-32233), total Akt (1:1,000; cat. no. sc-81434) and phosphorylated (p)-Akt (Ser473; 1:1,000; cat. no. sc-293125) were obtained from Santa Cruz Biotechnology, Inc., and the anti-mouse (1:5,000; TA130003) or anti-rabbit (1:5,000; TA130024) HRP-conjugated secondary antibodies were supplied by OriGene Technologies, Inc.. The protein bands were visualized using an enhanced chemiluminescence reagent (MilliporeSigma) using Image Lab Software 6.0.1 (Bio-Rad Laboratories, Inc.).

Statistical analysis. Data are presented as the mean \pm SEM and were analyzed using GraphPad Prism 6 (GraphPad Software, Inc.). Comparisons among different groups were performed using one-way ANOVA followed by Tukey's post hoc test. $\mathrm{P}<0.05$ was considered to indicate a statistically significant difference.

\section{Results}

DOX increases ACE mRNA expression levels. The expression levels of ACE mRNA were significantly increased in DOX-treated H9c2 cardiomyocytes compared with those in the control cells $(\mathrm{P}<0.01)$. However, treatment with benazepril- $\mathrm{HCl}$ and benazepril- $\mathrm{HCl}+\mathrm{DOX}$ resulted in a significant decrease in the ACE mRNA expression levels compared with those in the DOX-treated group $(\mathrm{P}<0.01 ;$ Fig. 1$)$.

Effects of DOX and benazepril-HCl on $\mathrm{H} 9 \mathrm{c} 2$ cell viability and $\mathrm{LDH}$ release. The $\mathrm{CCK}-8$ assay results revealed that

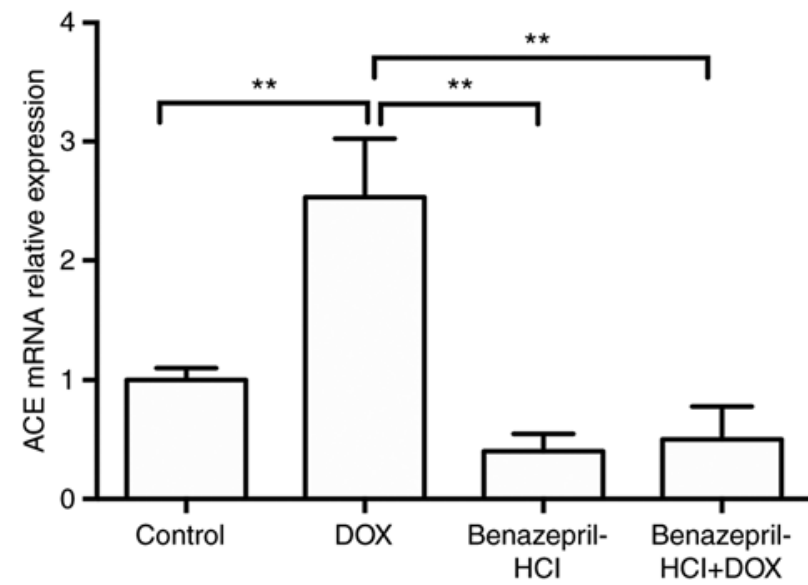

Figure 1. Expression levels of ACE mRNA in H9c2 cells. ACE mRNA expression levels were significantly upregulated in the DOX-treated group compared with those in the control group, and downregulated in the benazepril- $\mathrm{HCl}$ treatment group compared with those in the DOX-treated group. ${ }^{* *} \mathrm{P}<0.01$. $\mathrm{N}=3$ per group. ACE, angiotensin-converting enzyme; DOX, doxorubicin.

DOX treatment ( $2 \mu \mathrm{M} ; 24 \mathrm{~h})$ significantly decreased H9c2 cell viability compared with that of the control group by $56.3 \pm 3.6 \%$ $(\mathrm{P}<0.01$; Fig. 2A). Pretreatment with benazepril- $\mathrm{HCl}$ at 10 and $100 \mathrm{nM}$ did not increase the viability of DOX-treated cells ( $\mathrm{P}>0.05)$, whereas pretreatment with $1 \mu \mathrm{M}$ benazepril- $\mathrm{HCl}$ significantly enhanced cell viability by $34.2 \pm 4.2 \%(\mathrm{P}<0.01)$ compared with that in the DOX-treated group. The concentrations of benazepril- $\mathrm{HCl}>1 \mu \mathrm{M}$ did not provide an additional cytoprotective effect compared with that observed with $1 \mu \mathrm{M}$ ( $\mathrm{P}>0.05)$. These results suggested that benazepril- $\mathrm{HCl}$ at $1 \mu \mathrm{M}$ may protect cardiomyocytes from DOX-induced proliferation inhibition. Consequently, $1 \mu \mathrm{M}$ benazepril- $\mathrm{HCl}$ was used in subsequent experiments.

As presented in Fig. 2B, the level of $\mathrm{LDH}$ release in the supernatants of DOX-treated H9c2 cells was significantly increased $(\sim 189 \%)$ compared with that in the control group $(\mathrm{P}<0.01)$, and that of the benazepril-HCL + DOX treatment group was significantly decreased $24.6 \%(\mathrm{P}<0.05)$ compared with the DOX treatment group.

Benazepril-HCl protects $H 9 c 2$ cells against DOX-induced apoptosis. As presented in Fig. 3, DOX treatment $(2 \mu \mathrm{M}$; $24 \mathrm{~h}$ ) resulted in a significant increase in the apoptotic rate compared with that in the control group $(45.5 \pm 4.82$ compared with $8.6 \pm 1.21$; $\mathrm{P}<0.01$ ). However, benazepril-HCL pretreatment significantly decreased DOX-induced apoptosis to $25.8 \pm 2.1(\mathrm{P}<0.05)$ compared with that in the DOX treatment group. These results suggested that benazepril- $\mathrm{HCl}$ reduced the DOX-induced apoptosis in H9c2 cells.

Effects of benazepril-HCl on DOX-induced oxidative stress in $H 9 c 2$ cells. DOX-induced ROS production within the mitochondrial respiratory chain is considered a primary contributor to $\mathrm{H} 9 \mathrm{c} 2$ cell death (26). To assess whether the DOX-induced oxidative stress may be mitigated by pretreatment with benazepril-HCl, cellular ROS levels were measured in cells treated with benazepril- $\mathrm{HCl}$, DOX or benazepril- $\mathrm{HCl}+\mathrm{DOX}$ stained with $10 \mu \mathrm{M}$ DCFH-DA. As presented in Fig. 4A, the DCF fluorescence intensity was markedly increased by exposure to 
A

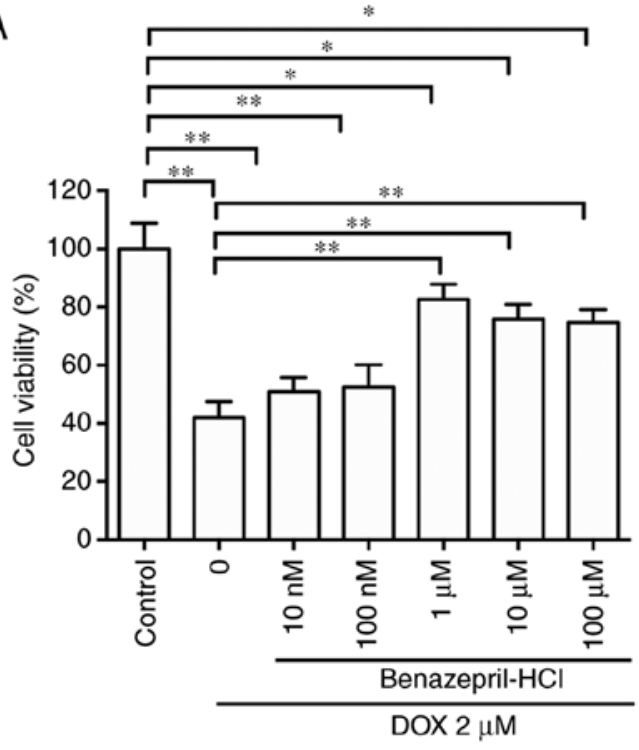

B

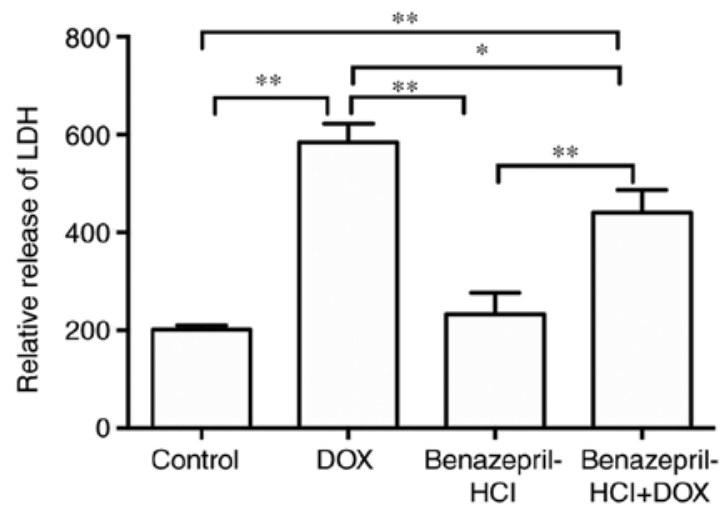

Figure 2. Effects of DOX and benazepril-HCl on $\mathrm{H} 9 \mathrm{c} 2$ cell viability and $\mathrm{LDH}$ release. (A) $\mathrm{H} 9 \mathrm{c} 2$ cells were pretreated for $1 \mathrm{~h}$ with benazepril-HCl at different concentrations $(0-100 \mu \mathrm{M})$ and further exposed to $2 \mu \mathrm{M}$ DOX for $24 \mathrm{~h}$. Cell viability was determined using a Cell Counting Kit- 8 assay, and the results were expressed as the percentage of viable cells relative to those in the control group. (B) H9c2 cardiomyocytes were treated with $1 \mu \mathrm{M}$ benazepril-HCl for $1 \mathrm{~h}$ and further exposed to $2 \mu \mathrm{M}$ DOX for $24 \mathrm{~h}$, after which the levels of $\mathrm{LDH}$ were measured. ${ }^{*} \mathrm{P}<0.05 ;{ }^{* *} \mathrm{P}<0.01 . \mathrm{N}=3$ per group. DOX, doxorubicin; $\mathrm{LDH}$, lactate dehydrogenase.
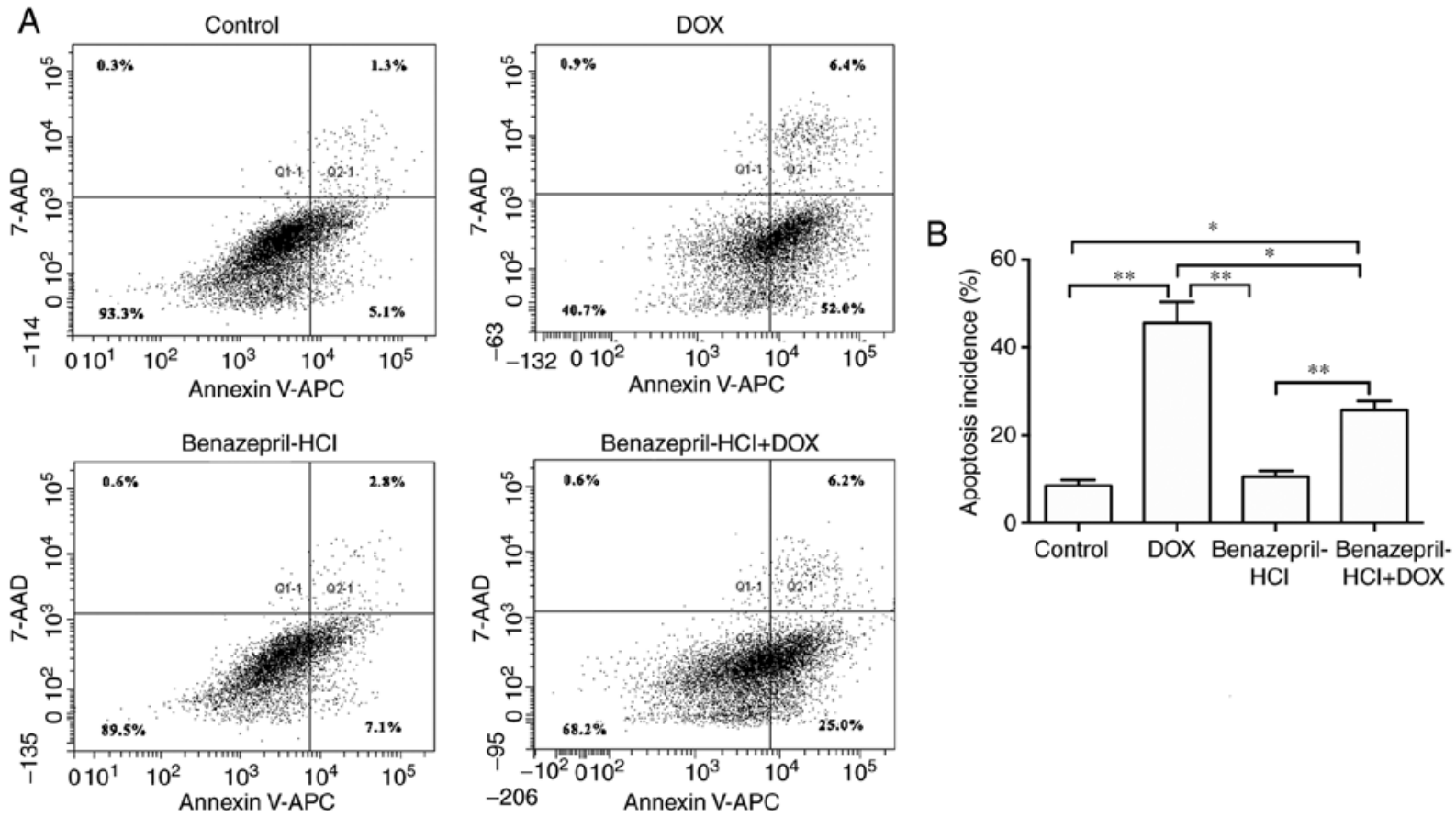

Figure 3. Benazepril-HCl protects H9c2 cells against DOX-induced apoptosis. (A) Apoptosis was evaluated by flow cytometry with an Annexin V-APC/7-AAD Apoptosis Detection kit in the control group, DOX-treated group, benazepril-HCl-treated group and benazepril-HCl + DOX-treated group. (B) Percentage of apoptotic cells out of $5 \times 10^{4}$ total cells were calculated from the flow cytometry in three independent experiments. $\mathrm{P}<0.05,{ }^{*} \mathrm{P}<0.01$. N=3 per group. DOX, doxorubicin.

DOX in the absence of benazepril- $\mathrm{HCl}$ compared with that in the control group, indicating that DOX induced oxidative stress in $\mathrm{H} 9 \mathrm{c} 2$ cells. However, pretreatment with benazepril- $\mathrm{HCl}$ significantly reduced DOX-induced intracellular ROS concentrations (Fig. 4B).

CAT, GSH-Px, SOD and MDA are commonly used as key biomarkers for oxidative stress and their changes are widely used as indicators of oxidative injury (27). The levels of these markers were measured to assess whether the DOX-induced metabolic imbalances in myocardial cells may be improved by pretreatment with benazepril- $\mathrm{HCl}$. In comparison with the controls, CAT, SOD and GSH-Px activity levels were significantly reduced in DOX-treated $\mathrm{H} 9 \mathrm{c} 2$ cells, whereas the MDA level was significantly increased (all $\mathrm{P}<0.01$ ). Compared with those in the DOX-treated group, following pretreatment with benazepril-HCl, cardiac CAT, SOD and GSH-Px activity 
A

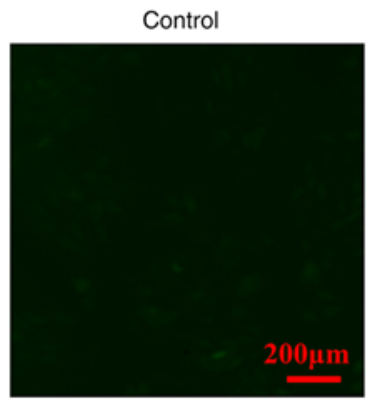

Benazepril-HCl

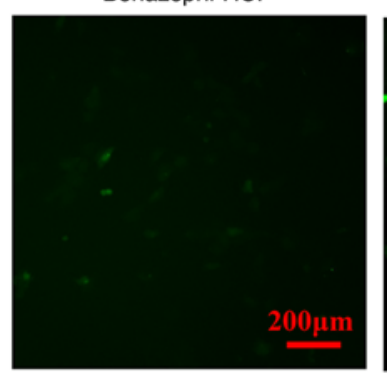

DOX

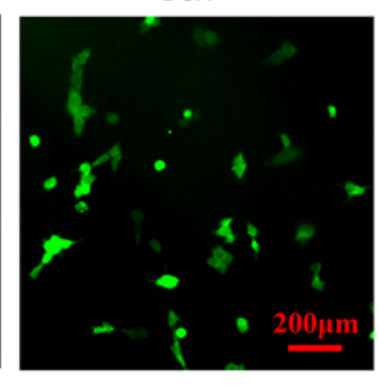

Benazepril- $\mathrm{HCl}+\mathrm{DOX}$

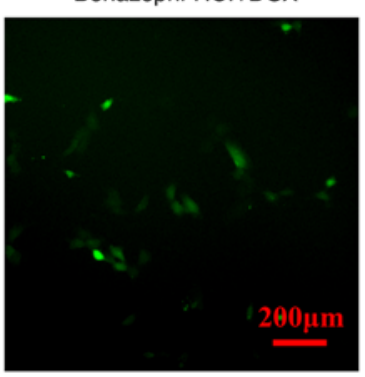

B
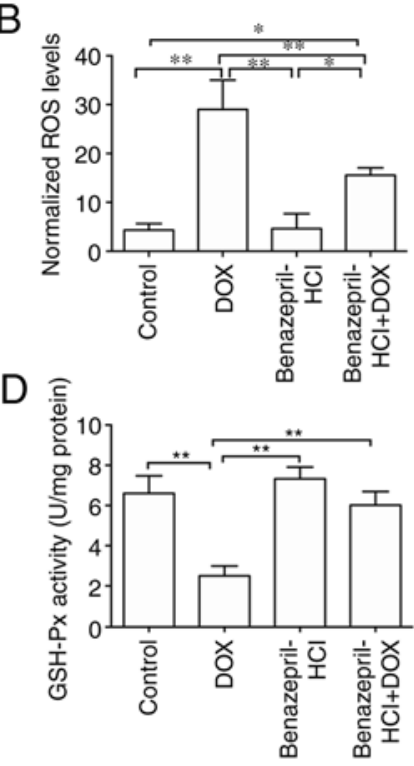

C

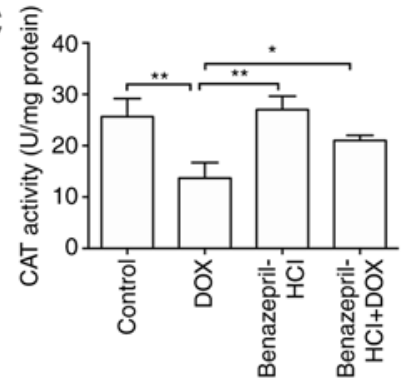

E

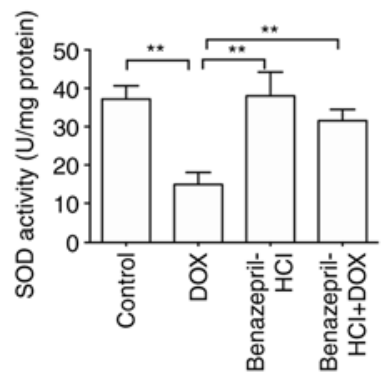

$\mathrm{F}$

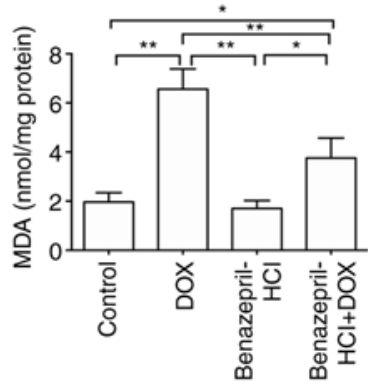

Figure 4. Effects of benazepril-HCl on DOX-induced oxidative stress in H9c2 cells. (A) DOX-induced ROS generation was inhibited in the presence of benazepril-HCl (scale bar, $200 \mathrm{~mm}$ ). (B) Quantified comparison of the ROS levels. Effects of benazepril-HCl on (C) CAT, (D) GSH-Px and (E) SOD activities, and (F) MDA concentrations in $\mathrm{H} 9 \mathrm{c} 2$ cells. ${ }^{*} \mathrm{P}<0.05,{ }^{* *} \mathrm{P}<0.01$. $\mathrm{N}=3$ per group. DOX, doxorubicin; ROS, reactive oxygen species; CAT, catalase; GSH-Px, glutathione peroxidase; SOD, superoxide dismutase; MDA, malondialdehyde.

levels were significantly enhanced and the MDA levels were significantly decreased $(\mathrm{P}<0.01$; Fig. $4 \mathrm{C}-\mathrm{F})$. These results suggested that benazepril-HCl prevented DOX-induced oxidative stress in cardiac cells.

Benazepril-HCl alleviates DOX-induced cardiomyocyte injury via PI3K/Akt signaling. The expression levels of proteins associated with the PI3K/Akt signaling pathway were determined by western blotting. As presented in Fig. 5A and B, the Akt phosphorylation levels were significantly reduced by DOX compared with those in the control group $(\mathrm{P}<0.01)$. However, benazepril- $\mathrm{HCl}+\mathrm{DOX}$ significantly recovered the phosphorylation levels of Akt compared with those in the DOX-treated group ( $\mathrm{P}<0.05$; Fig. 5A and B). Furthermore, MK2206, an Akt inhibitor, was used to reveal whether the PI3K/Akt pathway mediated the protective effect of benazepril-HCl on DOX-induced cardiomyocyte injury. MK2206 supplementation (benazepril- $\mathrm{HCl}+\mathrm{MK} 2206+\mathrm{DOX}$ group) inhibited Akt phosphorylation $(\mathrm{P}<0.05$, Fig. 5C and $\mathrm{D})$ and reduced cell viability $(\mathrm{P}<0.01$, Fig. $5 \mathrm{E})$ significantly, compared with those in the Benazepril + DOX treated group. In addition, LDH release was significantly increased after cells were incubated with MK2206 (benazepril- $\mathrm{HCl}+\mathrm{MK} 2206$ + DOX group) compared with that in the benazepril- $\mathrm{HCl}+\mathrm{DOX}$ group $(\mathrm{P}<0.05$; Fig. 5F). These results suggested that the protective effects of benazepril-HCl on DOX-induced cardiotoxicity may be due to a reduction in oxidative stress and the activation of the PI3k/Akt signaling.

\section{Discussion}

The present study aimed to investigate the protective roles and underlying mechanisms of benazepril- $\mathrm{HCl}$ on $\mathrm{DOX}$-induced cardiotoxicity. The results indicated that pretreatment with benazepril- $\mathrm{HCl}$ of $\mathrm{H} 9 \mathrm{c} 2$ cells alleviated DOX-induced oxidative stress, reduced the cardiomyocyte apoptosis and attenuated DOX-induced cardiotoxicity, suggesting that the use of benazepril- $\mathrm{HCl}$ may be a potential therapeutic approach to assist in the prevention of DOX-induced cardiotoxicity.

Anthracyclines, including DOX, are highly effective anticancer therapeutics; however, DOX-induced cardiac toxicity is a notable side effect of its long-term clinical use for anticancer treatment (28). Therefore, reducing DOX-induced cardiomyopathy is needed for the clinical success of this anticancer chemotherapy, which has been a challenge for pharmacologists and oncologists. Accumulating evidence has demonstrated the potential protective effects of ACEIs on the heart (29-32). In particular, the protective function of benazepril- $\mathrm{HCl}$ against heart failure has been confirmed in an isoproterenol-induced chronic heart failure model via amelioration of hypertrophy and 
A
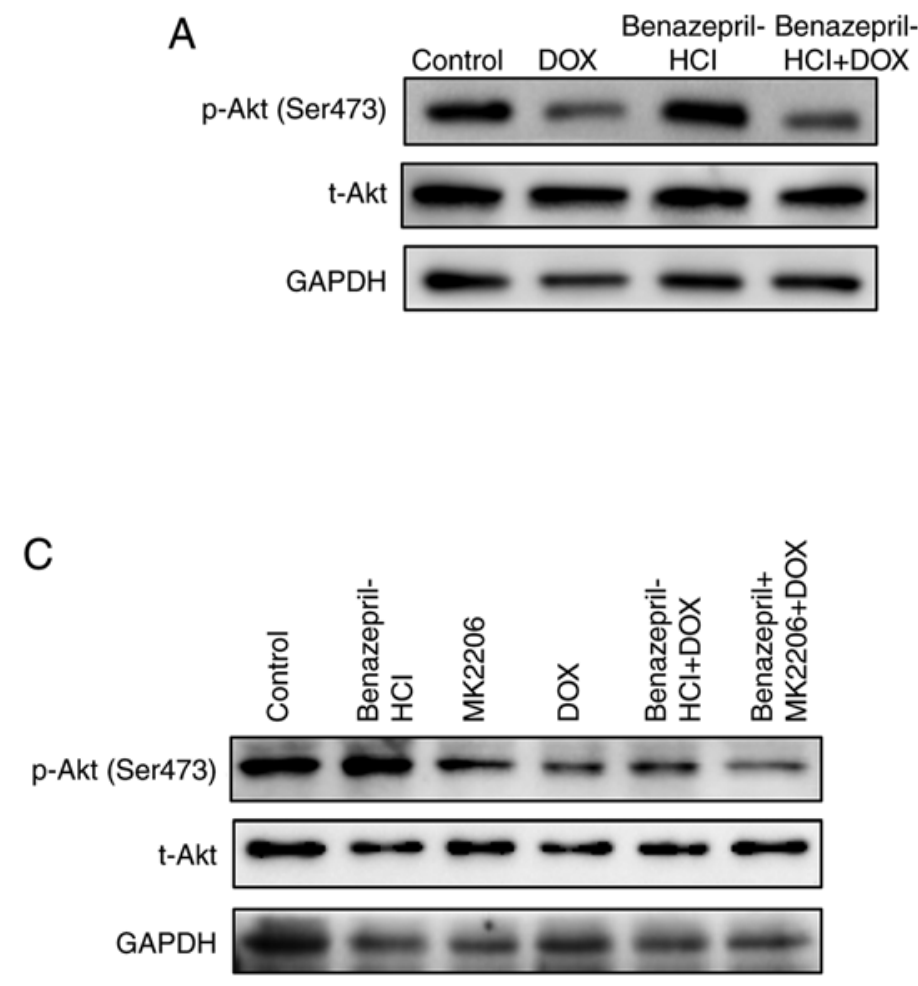

E

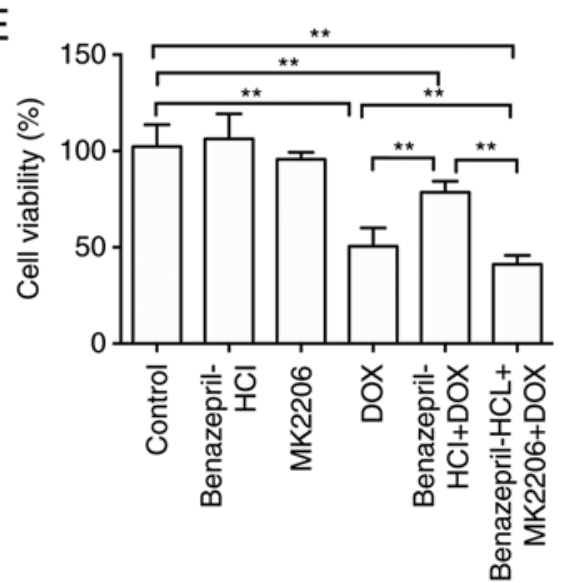

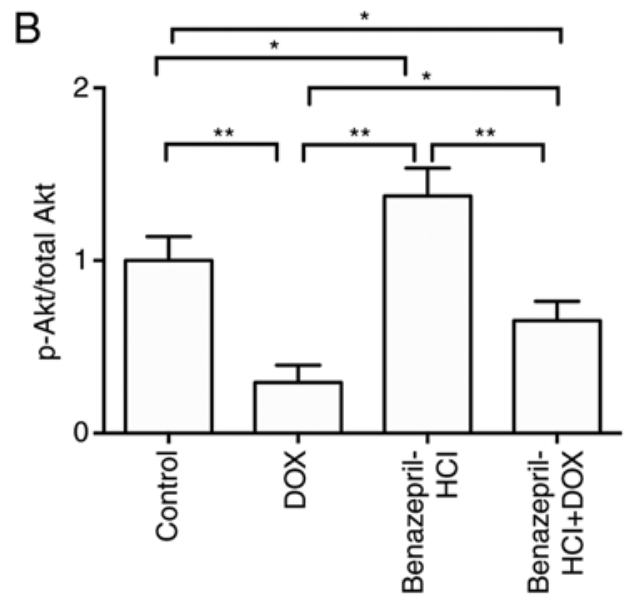

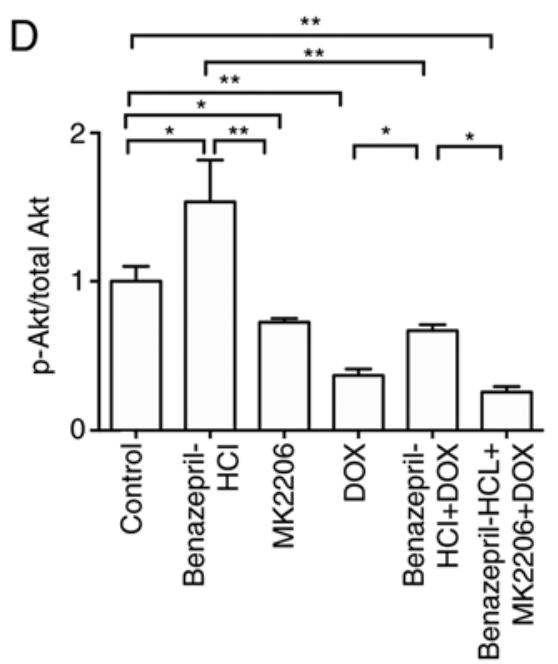

$\mathrm{F}$

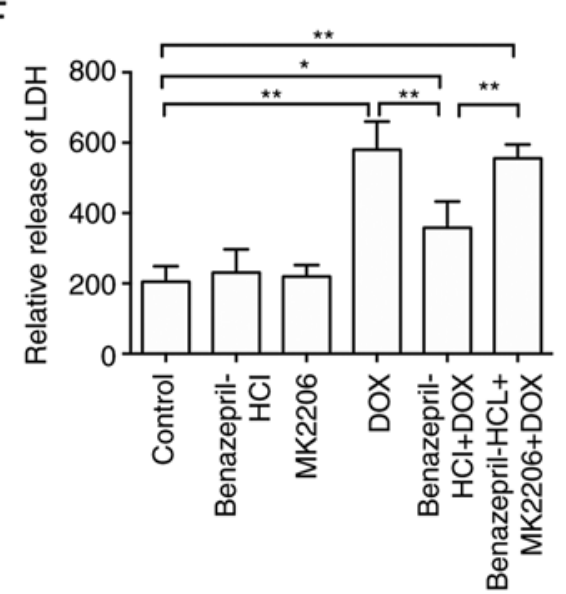

Figure 5. Effects of benazepril- $\mathrm{HCl}$ on activation of the Akt signaling pathway in DOX-treated $\mathrm{H} 9 \mathrm{c} 2$ cells. $\mathrm{H} 9 \mathrm{c} 2$ cells were treated with control or DOX $(2 \mu \mathrm{M})$ in the presence or absence of benazepril-HCl for $24 \mathrm{~h}$. t- and p-Akt protein levels were determined by (A) western blotting and (B) quantified as fold-changes compared with the control. Cells were pretreated with MK2206 and then exposed to DOX in the presence or absence of benazepril-HCl before DOX treatment for $24 \mathrm{~h}$. Akt phosphorylation level was determined by (C) western blotting and (D) quantified with total Akt as a loading control. (E) Cell viability was assayed. (F) LDH release was detected. ${ }^{*} \mathrm{P}<0.05,{ }^{* *} \mathrm{P}<0.01$. $\mathrm{N}=3$ per group. DOX, doxorubicin; t-, total; $\mathrm{p}$-, phosphorylated.

dysfunction of heart ventricles $(33,34)$. Additionally, alleviation of myocardial injury induced by ischemia and ventricular arrhythmia by benazepril-HCl has also been demonstrated (35). Furthermore, benazepril-HCl inhibits ventricular remodeling, myocardial hypertrophy and cardiac fibrosis in spontaneously hypertensive rats (36). Its anti-inflammatory activity prevents myocardial injury during septic shock, and its protective effect against aldosterone-induced myocardial injury has been identified to be similar to aldosterone inhibitors such as spironolactone and eplerenone (37).

The results of the present study revealed that the administration of benazepril- $\mathrm{HCl}$ at a dose of $1 \mu \mathrm{M}$ improved the 
viability of DOX-treated H9c2 cells. DOX treatment has been previously reported to increase the release of $\mathrm{LDH}$ from myocardial tissues (36). LDH has been demonstrated to be important for the diagnosis of DOX-induced myocardial cardiotoxicity (37). The present study revealed an increased level of LDH in the culture medium of DOX-treated H9c2 cells, whereas the $\mathrm{LDH}$ release was significantly inhibited in $\mathrm{H} 9 \mathrm{c} 2$ cells treated by a combination of benazepril-HCL and DOX. These results indicated the protective role of benazepril- $\mathrm{HCl}$ against DOX-induced cardiotoxicity in $\mathrm{H} 9 \mathrm{c} 2$ cells.

Despite the lack of understanding of the primary mechanism for DOX-induced cardiotoxicity, apoptosis of cardiomyocytes may serve a notable part in the side effects of DOX (38). The results of the present study confirmed a high level of apoptosis in DOX-treated H9c2 cells, whereas the apoptotic rate was significantly reduced in cells pretreated with benazepril- $\mathrm{HCl}$ compared with that in the cells treated with DOX alone. Therefore, the inhibition of cardiomyocyte apoptosis by pretreatment with benazepril- $\mathrm{HCl}$ may contribute to the alleviation of DOX-induced cardiotoxicity.

A high level of free radicals is an important contributor to DOX-induced cardiotoxicity (39). After DOX enters cardiomyocytes, it is reduced by mitochondrial enzymes into its semiquinone form, which produces ROS, including superoxide anion, hydrogen peroxide and hydroxyl radicals $(37,40)$. In comparison with other organs in mammalian species, the heart contains a lower concentration of enzymes, such as SOD, CAT and GSH-Px, for attenuating ROS toxicity and protecting against oxidative stress (8). Therefore, the heart is a primary organ associated with DOX-induced toxicity. In addition to the generation of damaging free radicals, endogenous antioxidant levels are also decreased by DOX, which may result in cardiomyocyte apoptosis (41). The results of the present study demonstrated that DOX decreased the expression levels of SOD, CAT and GSH-Px and increased cardiomyocyte apoptosis, which were consistent with previous studies $(41,42)$.

Due to of the occurence of oxidative stress after DOX treatment, antioxidant administration in combination with DOX may attenuate DOX-induced cardiotoxicity. Benazepril- $\mathrm{HCl}$ exhibits antioxidant properties that have been confirmed by its neuroprotective effects on intracerebral hemorrhage, excitotoxicity and diabetes-associated cognitive deficits, as well as its effects against melanoma, renal ischemia-reperfusion injury and pulmonary hypertension (43-45). The present study demonstrated that benazepril- $\mathrm{HCl}$ pretreatment reduced the levels of SOD, CAT and GSH-Px in DOX-treated H9c2 cells and decreased the DOX-induced ROS concentration in $\mathrm{H} 9 \mathrm{c} 2$ cells. These results suggested that benazepril- $\mathrm{HCl}$ pretreatment may protect $\mathrm{H} 9 \mathrm{c} 2$ cells from DOX-induced cardiotoxicity by decreasing oxidative stress.

Several previous studies have provided evidence that DOX-induced cardiac dysfunction is associated with reduced p-Akt/Akt levels (46-48). In addition, certain cadioprotective agents, such as neuregulin-1 $\beta$ and insulin-like growth factor-1, protect against DOX-induced cardiotoxicity by regulating the Akt-dependent signaling pathway $(49,50)$. The results of the present study revealed that pretreatment with benazepril- $\mathrm{HCl}$ significantly increased the phosphorylation of Akt. These results suggested that the protective effects of benazepril- $\mathrm{HCl}$ on DOX-induced cardiotoxicity may be due to a reduction in oxidative stress and the activation of the PI3k/Akt signaling. Furthermore, pretreatment with benazepril- $\mathrm{HCl}$ significantly enhanced the phosphorylation of Akt. Akt phosphorylation and $\mathrm{LDH}$ release in $\mathrm{H} 9 \mathrm{c} 2$ cells pretreated with benazepril- $\mathrm{HCl}$ were significantly inhibited by an Akt inhibitor MK2206. These results suggested that the protective effects of benazepril- $\mathrm{HCl}$ on DOX-induced cardiotoxicity may be due to a reduction in oxidative stress and the activation of the PI3k/Akt signaling.

The present study focused on the protction of benazepril against DOX-induced cardiotoxicity in $\mathrm{H} 9 \mathrm{c} 2$ cells but not in animals. Although H9c2 cell line cells are special clonal cardiomyoblasts that have a number of cardiomyocyte characteristics, increasing evidence suggests that there may be differences between $\mathrm{H} 9 \mathrm{c} 2$ cell experiments in vitro and animal models in vivo $(51,52)$. Thus, further studies in an animal model are needed to confirm the pharmacological antagonism of benazepril against DOX-induced cardiomyopathy.

In conclusion, in the present study, H9c2 cells were protected from DOX-induced cardiotoxicity by pretreatment with benazepril-HCl. This protection may be mediated by decreasing oxidative stress, reducing apoptosis and inducing alterations in the myocardial architecture. The present study supported the clinical benefits of co-administration of benazepril- $\mathrm{HCl}$ with DOX to reduce the risk of DOX-induced cardiotoxicity. However, further research is required to increase the understanding of the mechanisms of inhibition of oxidative stress and to confirm whether the administration of benazepril- $\mathrm{HCl}$ in combination with or before DOX treatment may interfere with the antitumor activity of DOX.

\section{Acknowledgements}

Not applicable.

\section{Funding}

This work was supported by The National Natural Science Foundation of China (grant nos. 81870221, 81670249,31271226 and 31071001).

\section{Availability of data and materials}

All data generated or analyzed during this study are included in this published article.

\section{Authors' contributions}

LZ conducted the experiments, collected the data and drafted the manuscript. XW obtained materials and conducted analysis. YZ acquired and analyzed data, provided general administrative support and confirmed the authenticity of all the raw data. GZ performed cell apoptosis examination and interpreted the data. YD and XC performed and analyzed the western blotting. WJ provided ideas, interpreted data, acquired funding and revised the manuscript. SW obtained materials, conducted analaysis, was a major contributor in writing the manuscript, and confirmed the authenticity of all the raw data. All authors have read and approved the final manuscript. 


\section{Ethics approval and consent to participate}

Not applicable.

\section{Patient consent for publication}

Not applicable.

\section{Competing interests}

The authors declare that they have no competing interests.

\section{References}

1. Rosen MR, Myerburg RJ, Francis DP, Cole GD and Marbán E: Translating stem cell research to cardiac disease therapies: Pitfalls and prospects for improvement. J Am Coll Cardiol 64 922-937, 2014

2. Khouri MG, Klein MR, Velazquez EJ and Jones LW: Current and emerging modalities for detection of cardiotoxicity in cardio-oncology. Future Cardiol 11: 471-484, 2015.

3. Angsutararux $P$, Luanpitpong $S$ and Issaragrisil $S$ : Chemotherapy-induced cardiotoxicity: Overview of the roles of oxidative stress. Oxid Med Cell Longev 2015: 795602, 2015.

4. Ma ZG, Kong CY, Wu HM, Song P, Zhang X, Yuan YP, Deng W and Tang QZ: Toll-like receptor 5 deficiency diminishes doxorubicin-induced acute cardiotoxicity in mice. Theranostics 10 11013-11025, 2020.

5. Cappetta D, De Angelis A, Sapio L, Prezioso L, Illiano M, Quaini F, Rossi F, Berrino L, Naviglio $S$ and Urbanek K: Oxidative stress and cellular response to doxorubicin: A common factor in the complex milieu of anthracycline cardiotoxicity. Oxid Med Cell Longev 2017: 1521020, 2017.

6. Nithipongvanitch R, Ittarat W, Cole MP, Tangpong J, Clair DK and Oberley TD: Mitochondrial and nuclear p53 localization in cardiomyocytes: Redox modulation by doxorubicin (Adriamycin)? Antioxid Redox Signal 9: 1001-1008, 2007.

7. Phaniendra A, Jestadi DB and Periyasamy L: Free radicals: Properties, sources, targets, and their implication in various diseases. Indian J Clin Biochem 30: 11-26, 2015.

8. Murabito A, Hirsch E and Ghigo A: Mechanisms of anthracycline-induced cardiotoxicity: Is mitochondrial dysfunction the answer? Front Cardiovasc Med 7: 35, 2020

9. Wallace KB, Sardão VA and Oliveira PJ: Mitochondrial determinants of doxorubicin-induced cardiomyopathy. Circ Res 126 926-941, 2020

10. Fu X, Kong L, Tang M, Zhang J, Zhou X, Li G, Wang H and Fu F: Protective effect of ocotillol against doxorubicin-induced acute and chronic cardiac injury. Mol Med Rep 9: 360-364, 2014.

11. Wang H, Yu P, Gou H, Zhang J, Zhu M, Wang ZH, Tian JW, Jiang YT and Fu FH: Cardioprotective effects of 20 (S)-ginsenoside Rh2 against doxorubicin-induced cardiotoxicity in vitro and in vivo. Evid Based Complement Alternat Med 2012 506214, 2012.

12. Nazmi AS, Ahmad SJ, Pillai KK, Akhtar M, Ahmad A and Najmi AK: Protective effects of Bombyx mori, quercetin and benazepril against doxorubicin induced cardiotoxicity and nephrotoxicity. J Saudi Chem Soc 20 (Suppl 1): S573-S578, 2016.

13. Ganatra S, Nohria A, Shah S, Groarke JD, Sharma A, Venesy D, Patten R, Gunturu K, Zarwan C, Neilan TG, et al: Upfront dexrazoxane for the reduction of anthracycline-induced cardiotoxicity in adults with preexisting cardiomyopathy and cancer: A consecutive case series. Cardiooncology 5: 1, 2019.

14. Sacco G, Bigioni M, Evangelista S, Goso C, Manzini S and Maggi CA: Cardioprotective effects of zofenopril, a new angiotensin-converting enzyme inhibitor, on doxorubicin-induced cardiotoxicity in the rat. Eur J Pharmacol 414: 71-78, 2001.

15. Guglin M, Munster P, Fink A and Krischer J: Lisinopril or Coreg $\mathrm{CR}$ in reducing cardiotoxicity in women with breast cancer receiving trastuzumab: A rationale and design of a randomized clinical trial. Am Heart J 188: 87-92, 2017.

16. Spallarossa P, Guerrini M, Arboscello E and Sicbaldi V: Enalapril and carvedilol for preventing chemotherapy-induced left ventricular systolic dysfunction. J Am Coll Cardiol 62: $2451-2452,2013$
17. Choi HS, Park ES, Kang HJ, Shin HY, Noh CI, Yun YS, Ahn HS and Choi JY: Dexrazoxane for preventing anthracycline cardiotoxicity in children with solid tumors. J Korean Med Sci 25: 1336-1342, 2010.

18. Octavia Y, Tocchetti CG, Gabrielson KL, Janssens S, Crijns HJ and Moens AL: Doxorubicin-induced cardiomyopathy: From molecular mechanisms to therapeutic strategies. J Mol Cell Cardiol 52: 1213-1225, 2012.

19. Zablocki D and Sadoshima J: Angiotensin II and oxidative stress in the failing heart. Antioxid Redox Signal 19: 1095-1109, 2013.

20. King JN, Font A, Rousselot JF, Ash RA, Bonfanti U, Brovida C, Crowe ID, Lanore D, Pechereau D, Seewald W and Strehlau G: Effects of benazepril on survival of dogs with chronic kidney disease: A multicenter, randomized, blinded, placebo-controlled clinical trial. J Vet Intern Med 31: 1113-1122, 2017.

21. Chan KK, Buch A, Glazer RD, John VA and Barr WH: Site-differential gastrointestinal absorption of benazepril hydrochloride in healthy volunteers. Pharm Res 11: 432-437, 1994.

22. Muñoz-Durango N, Fuentes CA, Castillo AE, GonzálezGómez LM, Vecchiola A, Fardella CE and Kalergis A: Role of the renin-angiotensin-aldosterone system beyond blood pressure regulation: Molecular and cellular mechanisms involved in end-organ damage during arterial hypertension. Int J Mol Sci 17: 797, 2016.

23. Parving HH: Diabetic nephropathy. Prevention and treatment. Kidney Int 60: 2041-2055, 2001.

24. Yim HE and Yoo KH: Renin-angiotensin system-considerations for hypertension and kidney. Electrolyte Blood Press 6: 42-50, 2008.

25. Livak KJ and Schmittgen TD: Analysis of relative gene expression data using real-time quantitative PCR and the 2(-Delta Delta C(T)) method. Methods 25: 402-408, 2001.

26. Wang Z, Wang J, Xie R, Xie R, Liu R and Lu Y: Mitochondria-derived reactive oxygen species play an important role in doxorubicin-induced platelet apoptosis. Int J Mol Sci 16: 11087-11100, 2015

27. Kuyumcu F and Aycan A: Evaluation of oxidative stress levels and antioxidant enzyme activities in burst fractures. Med Sci Monit 24: 225-234, 2018.

28. Ma ZG, Yuan YP, Xu SC, Wei WY, Xu CR, Zhang X, Wu QQ, Liao HH, Ni J and Tang QZ: CTRP3 attenuates cardiac dysfunction, inflammation, oxidative stress and cell death in diabetic cardiomyopathy in rats. Diabetologia 60: 1126-1137, 2017.

29. Kumari H, Huang WH and Chan MWY: Review on the role of epigenetic modifications in doxorubicin-induced cardiotoxicity. Front Cardiovasc Med 7: 56, 2020.

30. Munger MA: Use of angiotensin receptor blockers in cardiovascular protection: Current evidence and future directions. P T 36: 22-40, 2011.

31. Haybar H, Shahrabi S, Deris Zayeri Z and Pezeshki S: Strategies to increase cardioprotection through cardioprotective chemokines in chemotherapy-induced cardiotoxicity. Int J Cardiol 269: 276-282, 2018

32. Yakubova A, Thorrez L, Svetlichnyy D, Zwarts L, Vulsteke V, Laenen G, Oosterlinck W, Moreau Y, Dehaspe L, Van Houdt J, et al: ACE-inhibition induces a cardioprotective transcriptional response in the metabolic syndrome heart. Sci Rep 8: 16169, 2018

33. Gujral DM, Lloyd G and Bhattacharyya S: Effect of prophylactic betablocker or ACE inhibitor on cardiac dysfunction and heart failure during anthracycline chemotherapy \pm trastuzumab. Breast 37: 64-71, 2018

34. Steele JL, Henik RA and Stepien RL: Effects of angiotensin-converting enzyme inhibition on plasma aldosterone concentration, plasma renin activity, and blood pressure in spontaneously hypertensive cats with chronic renal disease. Vet Ther 3: 157-166, 2002

35. Wan W, Jiang X, Li X, Zhang C and Yi X: Silencing of angiotensin-converting enzyme by RNA interference prevents H9c2 cardiomyocytes from apoptosis induced by anoxia/reoxygenation through regulation of the intracellular renin-angiotensin system. Int J Mol Med 32: 1380-1386, 2013.

36. Li YW, Li YM, Hon Y, Wan QL, He RL, Wang ZZ and Zhao CH: AT1 receptor modulator attenuates the hypercholesterolemia-induced impairment of the myocardial ischemic post-conditioning benefits. Korean Circ J 47: 182-192, 2017.

37. Nie P, Meng F, Zhang J, Wei X and Shen C: Astragaloside IV exerts a myocardial protective effect against cardiac hypertrophy in rats, partially via activating the $\mathrm{Nrf} 2 / \mathrm{HO}-1$ signaling pathway. Oxid Med Cell Longev 2019: 4625912, 2019. 
38. Maron BA and Leopold JA: Aldosterone receptor antagonists: Effective but often forgotten. Circulation 121: 934-939, 2010.

39. Gorini S, De Angelis A, Berrino L, Malara N, Rosano G and Ferraro E: Chemotherapeutic drugs and mitochondrial dysfunction: Focus on doxorubicin, trastuzumab, and sunitinib. Oxid Med Cell Longev 2018: 7582730, 2018.

40. Jing S, Sun G, Cui X, Meng X, Qin M and Sun X: Myricitrin protects against doxorubicin-induced cardiotoxicity by counteracting oxidative stress and inhibiting mitochondrial apoptosis via ERK/P53 pathway. Evid Based Complement Alternat Medi 2016: 6093783, 2016.

41. Varga ZV, Ferdinandy P, Liaudet L and Pacher P: Drug-induced mitochondrial dysfunction and cardiotoxicity. Am J Physiol Heart Circ Physiol 309: H1453-H1467, 2015.

42. Mantawy EM, El-Bakly WM, Esmat A, Badr AM and EI-Demerdash E: Chrysin alleviates acute doxorubicin cardiotoxicity in rats via suppression of oxidative stress, inflammation and apoptosis. Eur J Pharmacol 728: 107-118, 2014.

43. Kurutas EB: The importance of antioxidants which play the role in cellular response against oxidative/nitrosative stress: Current state. Nutr J 15: 71, 2016.

44. Wu YZ, Zhang L, Wu ZX, Shan TT and Xiong C: Berberine ameliorates doxorubicin-induced cardiotoxicity via a SIRT1/p66Shc-mediated pathway. Oxid Med Cell Longev 2019: 2150394, 2019

45. Malik ZA, Singh M and Sharma PL: Neuroprotective effect of momordica charantia in global cerebral ischemia and reperfusion induced neuronal damage in diabetic mice. J Ethnopharmacol 133: 729-734, 2011.

46. Jiang M, Li J, Peng Q, Liu Y, Liu W, Luo C, Peng J, Li J, Yung KK and Mo Z: Neuroprotective effects of bilobalide on cerebral ischemia and reperfusion injury are associated with inhibition of pro-inflammatory mediator production and down-regulation of JNK1/2 and p38 MAPK activation. J Neuroinflammation 11: 167,2014
47. Singal PK, Li T, Kumar D, Danelisen I and Iliskovic N: Adriamycin-induced heart failure: Mechanism and modulation. Mol Cell Biochem 207: 77-86, 2000.

48. Taniyama Y and Walsh K: Elevated myocardial Akt signaling ameliorates doxorubicin-induced congestive heart failure and promotes heart growth. J Mol Cell Cardiol 34: 1241-1247, 2002.

49. Timolati F, Ott D, Pentassuglia L, Giraud MN, Perriard JC, Suter TM and Zuppinger C: Neuregulin-1 beta attenuates doxorubicin-induced alterations of excitation-contraction coupling and reduces oxidative stress in adult rat cardiomyocytes. J Mol Cell Cardiol 41: 845-854, 2006.

50. Lai HC, Liu TJ, Ting CT, Sharma PM, Wang PH: Insulin-like growth factor-1 prevents loss of electrochemical gradient in cardiac muscle mitochondria via activation of PI3 kinase/Akt pathway. Mol Cell Endocrinol 205: 99-106, 2003.

51. Watkins SJ, Borthwick GM and Arthur HM: The H9C2 cell line and primary neonatal cardiomyocyte cells show similar hypertrophic responses in vitro. In Vitro Cell Dev Biol Anim 47: 125-131, 2001.

52. Branco AF, Pereira SP, Susana G, Gusev O, Rizvanov AA and Olivira PJ: Gene expression profiling of $\mathrm{H} 9 \mathrm{c} 2$ myoblast differentiation towards a cardiac-like phenotype. PLoS One 10: $\mathrm{e} 0129303,2015$.

This work is licensed under a Creative Commons Attribution-NonCommercial-NoDerivatives 4.0 International (CC BY-NC-ND 4.0) License. 